\title{
El obispo Lope de Barrientos y la sociedad judeoconversa: su intervención en el debate doctrinal en torno a la «Sentencia-Estatuto» de Pero Sarmiento
}

\author{
EnRIQUe Cantera Montenegro*
}

\begin{abstract}
RESUMEN
El proceso de integración de los judeoconversos en la sociedad hispanocristiana resultó profundamente controvertido, y constituyó una de las cuestiones más relevantes de la Castilla del siglo XV. Los años centrales de la centuria decimoquinta estuvieron

marcados por una interesante polémica doctrinal en torno a la llamada "Sentencia-Estatuto" de Pero Sarmiento, que ordenaba la exclusión de los judios y de los judeoconversos

de todos los oficios públicos de la ciudad de Toledo. En este debate intervino el obispo de Cuenca Lope de Barrientos, una de las personalidades más destacadas del panorama político

y eclesiástico de la Castilla de mediados del siglo XV. Junto a otras destacadas figuras del momento (Fernán Díaz de Toledo, Alonso de Cartagena, Juan de Torquemada), Barrientos defendió la plena integración de los judeoconversos en
\end{abstract}

\section{ABSTRACT}

The integration process of the jewish converts in the christian spanish society was highly controversial and it suppoused one of the most relevant subjects in the Castile of the XV century. The central years of that century were characterized by an interesting doctrinal debate around the so - called Pero Sarmiento's "Sentencia-Estatuto", that ordered the exclusion of jewish and convert jewish from all civil service jobs of the city of Toledo. The bishop of Cuenca, Lope de Barrientos, one of the most relevant political and ecclesiastic figure of that time, took part in that debate. In collaboration with other outstanding people (Fernán Diaz de Toledo, Alonso de Cartagena, Juan de Torquemada), Barrientos supported the full integration of the convent jewish in the christian spanish society, as well as the need of tolerance towards the new converts to

* UNED. 
la sociedad hispanocristiana, así como la necesidad de tolerancia hacia los recién convertidos al cristianismo en tanto durase el proceso de adoctrinamiento en su nueva religión.

El debate se prolongó durante la segunda mitad del siglo $\mathrm{XV}$, imponiéndose a la larga quienes propugnaban la adopción de medidas

restrictivas para con la actuación pública de los cristianos nuevos, que cristalizarían en el apartamiento de los judaizantes $y$ de sus descendientes del ejercicio de oficios públicos y en la aparición de los «estatutos de limpieza de sangre", ya en vísperas de la Modernidad. christianism during the process of indoctrination to their new religion. The debate continued along the second half of the XV century, finally won by those who supported the implementation of restrictions for the civil service participation of the new christians. The consequence was the exclusion of the jewish and their descendants from the civil service and the entry into force of the epurity of blood protocol", on the eve of the Modernity.

\section{PREÁMBULO}

Desde hace algún tiempo, la figura del obispo Lope de Barrientos es reconocida como una de las personalidades más destacadas del panorama político y eclesiástico de la Castilla de mediados del siglo XV.

Su importante participación en la vida política, que le llevó a ocupar, entre otras altas dignidades, la de canciller mayor durante el reinado de Enrique IV de Castilla, de quien fue preceptor, no fue en menoscabo de una también muy intensa actividad en los terrenos eclesiástico e intelectual, en los que es fácil observar cómo una de las líneas básicas de su pensamiento fue la unidad de la Iglesia cristiana y de sus miembros, lo que es fruto tanto de sus íntimas convicciones religiosas como de sus planteamientos de carácter social.

Y fue precisamente la defensa de este principio lo que llevó al obispo de Cuenca a intervenir de forma activa en el interesante debate doctrinal que a fines del año 1449 se suscitó en el reino de Castilla, en torno a la controvertida decisión de las autoridades toledanas de apartar a los judeoconversos de los oficios públicos que venían desempeñando hasta este momento sin ningún tipo de restricción y, de forma más amplia, acerca de su plena integración en la sociedad hispanocristiana.

La polémica en torno a los judeoconversos es una constante del siglo $x \vee$ hispano, pero en ningún momento alcanzó tanta relevancia como a mediados de esta centuria en torno a los acontecimientos toledanos. A través 
tanto de algunos de sus escritos como de otros textos de autores que intervinieron activamente en este debate, podemos conocer la toma de posición del obispo Lope de Barrientos en torno a una cuestión que se planteaba como fundamental en la sociedad hispana del siglo XV.

\section{LA REVUELTA TOLEDANA DE 1449 Y SU SIGNIFICADO}

La primera mitad del siglo xv viene marcada en los reinos hispanos por un clima de relativa tranquilidad en las relaciones entre las comunidades cristiana y judía, después de los violentos acontecimientos del año 1391. Incluso las predicaciones promovidas principalmente por san Vicente Ferrer se distinguieron por la ausencia de violencia física contra los judíos.

Sin embargo, la segunda mitad de esta centuria ofrece un panorama muy diferente. Las profundas contradicciones que subyacían en la sociedad castellana afloraron con gran virulencia e impedieron las escasas posibilidades de acuerdo entre cristianos y judíos. En este momento es también fácilmente apreciable la gran interdependencia de los problemas judío y converso, que tienen una base común en la que se interrelacionan profundamente factores económico-sociales, políticos y religiosos.

El reinado de Juan II de Castilla estuvo marcado por la rebelión nobiliaria y la oposición de los concejos, a lo que vino a unirse el enfrentamiento entre cristianos viejos y cristianos nuevos, que fue una constante en el medio urbano castellano también a lo largo del tercer cuarto del siglo $\mathrm{XV}$, hasta que los Reyes Católicos restablecieron el orden político interno ${ }^{1}$.

En definitiva, a lo largo del siglo xv — prácticamente en todas las generaciones de esta centuria-, distintos autores plantearon el problema de los conversos, y buscaron una solución del mismo desde muy distintas perspectivas. Pero la verdadera polémica se planteó en toda su crudeza en los últimos años del reinado de Juan II y en los primeros del de Enrique IV.

El acontecimiento más relevante es el que tuvo por escenario la ciudad de Toledo donde, en el año 1449, estalló una violenta revuelta anticonversa que fue seguida de una profunda polémica doctrinal, en la que diversos autores tomaron partido en pro o en contra de los conversos y de

\footnotetext{
1 Para un planteamiento general sobre los orígenes del problema converso en la Castilla del siglo $\mathrm{XV}$, y sus presupuestos básicos, resulta sumamente clarificador el capítulo XI de la obra, ya clásica, de Yitzhak BAER, Historia de los Judíos en la España Cristiana (Madrid. Altalena, 1981, 2 vols.), titulado «Resurgimiento de las ruinas y el problema de los conversos (el siglo XV)».
} 
su plena integración en la sociedad hispanocristiana de la que, al menos en teoría, formaban ya parte.

La revuelta toledana de 1449 , estudiada detalladamente por el profesor Benito Ruano ${ }^{2}$, presenta algunas características innovadoras en la evolución del antijudaísmo castellano, pese a que la misma no fue dirigida directamente contra los judíos toledanos, sino contra los judeoconversos. Algunos autores han visto en este levantamiento, y en los textos y obras surgidas en torno a él, las primeras manifestaciones de un sentimiento «racista» en el planteamiento de las relaciones entre cristianos y judíos ${ }^{3}$. En los acontecimientos toledanos se encuentran, no en vano, los precedentes remotos de los llamados «estatutos de limpieza de sangre», que tanta trascendencia tuvieron a lo largo de la Edad Moderna hispana.

En esta revuelta convergen varios elementos: la pugna politica entre la gran nobleza castellana y los partidarios del fortalecimiento del poder real, seguidores de don Álvaro de Luna; la conflictividad social propia del ámbito urbano, que se expresa en los enfrentamientos banderizos por el control político de las ciudades; y el tradicional antijudaísmo, compartido cada vez por más amplias capas de la sociedad castellana.

En definitiva, en la revuelta de 1449 pueden vislumbrarse tres conflictos simultáneos: un conflicto social, que se manifiesta en una insurrección popular de carácter antifiscal; un conflicto político, en cuanto la revuelta supone un levantamiento contra la figura del condestable don Álvaro de Luna, representante más destacado de la autoridad regia; y un conflicto anticonverso, en el que se manifiesta una vertiente popular, que combina el odio religioso con la conflictividad social, y otra vertiente mucho más teórica, que se materializa en la Sentencia-Estatuto de Pero Sarmiento, surgida en el seno de la oligarquía urbana toledana con el ánimo de privar a los judeonconversos del ejercicio de oficios públicos ${ }^{4}$.

La Sentencia-Estatuto de Pero Sarmiento, hecha pública el 5 de junio de 1449, supone la plasmación práctica del espíritu que anima la revuelta toledana. Después de acusar a los judeoconversos de graves delitos, y

2 Eloy Benito Ruano, Toledo en el siglo xV. Vida política. Madrid, 1961, y Los origenes del problema converso. Barcelona. El Albir, 1976.

3 Así lo señala, por ejemplo, José M." Monsalvo Antón, Teoría y evolución de un conflicto social. El antisemitismo en la Corona de Castilla en la Baja Edad Media. Madrid. Siglo XXI, 1985, pág. 297.

Bastantes decenios antes Yitzhak BAER (Op. cit,, II, pág. 530) se refería a la rebelión toledana de 1449 como la primera "guerra civil racial».

4 José M. MONSALvo ANTÓn, Teoría y evolución de un conflicto social. El antisemitismo en la Corona de Castilla en la Baja Edad Media, págs. 300-302. 
en especial de su profunda enemistad hacia los cristianos viejos, ordena la exclusión de los judíos y de sus descendientes de todos los cargos y oficios públicos de la ciudad de Toledo y de su jurisdicción. Asimismo les niega la posibilidad de actuar como escribanos públicos y como testigos en juicios contra cristianos viejos.

A lo largo de su exposición, la Sentencia-Estatuto hace continua referencia a la que considera excesiva influencia social de los judeoconversos, que éstos utilizarían para oprimir y robar a los cristianos viejos. La razón de esta forma de actuar obedecería a la enemistad visceral que sentirían hacia los cristianos viejos, que les habría sido transmitida por los judíos; a este respecto, se hace alusión a la entrega de la ciudad de Toledo por parte de los judíos a los musulmanes invasores, y se acusa a los judeoconversos de repetir esta inicua acción al solicitar la intervención de don Álvaro de Luna contra la ciudad sublevada.

Por todo ello, se acuerda la inhabilitación de los judeoconversos para el ejercicio de oficios públicos. La justificación de esta drástica medida se fundamenta en el derecho canónico, en concreto en un pasaje del IV Concilio de Toledo -en torno al que se articuló buena parte del debate doctrinal acerca de los judeoconversos-, y en un supuesto decreto otorgado por un rey Alfonso, del que no existe ninguna noticia en textos jurídicos, ni históricos, ni apologéticos, y que lo más probable es que no sea sino producto de la fantasía interesada de los redactores de la Sentencia-Estatuto.

Pese a que fue anulada muy pronto, la Sentancia-Estatuto tuvo una enorme trascendencia en la evolución de las relaciones entre cristianos viejos y cristianos nuevos, pues dio lugar a una alteración profunda en las actitudes mentales de la sociedad castellana en el tránsito de la Edad Media a la Moderna. Como se ha señalado anteriormente, es ya un claro precedente de los "estatutos de limpieza de sangre», por lo que su trascendencia histórica va mucho más allá de los acontecimientos concretos de la revuelta toledana de 1449. Supone, así pues, un primer y grave obstáculo en el lento proceso de unificación socio-religiosa entre cristianos viejos y nuevos, que se había desarrollado hasta mediados del siglo XV tras la conversión masiva de judíos al cristianismo, y que condujo a una profunda separación, primero instintiva y más tarde jurídicamente positiva, entre cristianos viejos y judeoconversos.

\section{EL DEBATE DOCTRINAL EN TORNO A LOS JUDEOCONVERSOS}

La promulgación del decreto de Pero Sarmiento suscitó una amplia polémica en la sociedad culta castellana desde el verano de 1449, que se 
prolongó durante toda la segunda mitad del siglo $\mathrm{xV}$. En este debate fue frecuente el recurso a todo tipo de textos bíblicos, canónicos y jurídico-legislativos, así como a muy diversos argumentos teológicos, jurídicos e históricos, lo que resulta demostrativo del estado oficial y legal al que había llegado el proceso de escisión entre cristianos viejos y cristianos nuevos en la sociedad castellana. Lo que en este momento se plantea, sin ambages de ningún tipo, es la cuestión del derecho a la plena participación en la vida pública de un importante sector de la sociedad lo que, de llevarse a la práctica, haría cuestionable su consideración como un todo unitario.

Los defensores del principio de la igualdad absoluta entre cristianos esgrimieron sólidas razones teológicas y canónicas: la unidad originaria del género humano a partir de unos mismos padres; la universalidad de la Redención; el precepto evangélico de la fraternidad; el linaje hebreo del propio Jesucristo y de la Virgen María; etc.

Asimismo aluden también a la mezcla de sangre judía que presentan las más señaladas familias castellanas. Este argumento sería explotado en el siglo XVI por los «Libros verdes» (Libro Verde de Aragón), «Tizones de la nobleza» (Tizón de la Nobleza de España) y demás padrones de denuncia genealógica del momento que, con evidente exageración, buscaban una ascendencia hebrea en casi todas las familias nobles españolas.

Es importante destacar que la defensa de los judeoconversos y de su plena integración en la sociedad hispanocristiana fue acompañada, con frecuencia, de duros ataques por parte de los mismos autores contra los judíos, a los que acusaban de contumacia religiosa.

Casi todos estos autores son eclesiásticos, en su mayor parte judeoconversos o descendientes suyos, como también lo eran quienes por las mismas fechas escribían obras teológicas intentando convencer a los judíos del error en el que se encontraban: Pablo de Santa María, antiguo rabino mayor de Burgos, autor del Scrutinium Scripturarum; Jerónimo de Santa $\mathrm{Fe}$, a quien se debe el tratado denominado Hebraeomastix; Pedro de la Caballería, autor del Zelus Christi contra Judaeos, Sarracenos et Infideles; Alonso de Valladolid, quien escribió el Mostrador de Justicia; o fray Alonso de Espina, autor del Fortalitium Fidei contra Judaeos.

Los partidarios del establecimiento de medidas discriminatorias para con los cristianos nuevos se basaban en fuentes textuales muy similares a las de sus adversarios, y en sus escritos es fácilmente perceptible una extremada pasión, claramente demagógica.

La primera reacción opuesta a la Sentencia-Estatuto de Pero Sarmiento corresponde al obispo de Burgos, don Alonso de Cartagena, autor de la 
obra titulada Defensorium Unitatis Christianae, y miembro de una importantísima familia de judeoconversos, que tuvo un muy destacado papel en la vida política, religiosa y cultural de Castilla a lo largo de la primera mitad del siglo $\mathrm{XV}^{5}$.

Alonso de Cartagena fue, además de un destacado representante de la Iglesia española de su tiempo, un jurista, un diplomático y un moralista, con una vasta formación en estudios clásicos y bíblicos. Su excelencia intelectual, y su elevada preparación en cuestiones políticas, sociales y religiosas, se hace patente en sus principales tratados, como el Doctrinal de caballeros o el Defensorium Unitatis Christianae, en los que se hace evidente, ante todo, una profunda preocupación de carácter jurídico-moral ${ }^{6}$.

El Defensorium Unitatis Christianae es la obra más extensa y completa de todas las que fueron escritas en favor de los conversos. Redactada en latín, está dirigida al rey Juan II, y en ella se insiste en la unidad del género humano desde Adán, así como en la universalidad de la Redención, aplicando el calificativo de herejes y cismáticos a quienes se muestran partidarios de políticas discriminatorias hacia los cristianos nuevos. Esta obra es un buen ejemplo de lo que fue la actitud oficial de la Iglesia en esta cuestión, claramente condenatoria de la doctrina proclamada en la Sentencia-Estatuto.

En este momento del debate las dos partes enfrentadas solicitaron la intervención arbitral pontificia. De este modo, el proceso que había sido incoado a Pero Sarmiento por orden de Juan II fue remitido a Roma, con una doble acusación: una de carácter religioso, consistente en introducir una escisión en el cuerpo místico de la Iglesia, y otra de carácter político, por cuanto la revuelta suponía un atentado contra la autoridad regia, que emana de la divina.

Sarmiento, por su parte, envió una delegación a Roma con el fin de exponer ante el pontífice las razories de su actuación y, de este modo, lograr una sanción de la Sentencia-Estatuto. Pero esta delegación no al-

\footnotetext{
5 El estudio más completo sobre la figura de Alonso de Cartagena sigue siendo el ya clásico de Luciano Serrano, Los conversos don Pablo de Santa María y don Alonso de Cartagena. Madrid, 1942. Asimismo resulta de gran interés el estudio de Francisco Cantera Burgos, Alvar Garcia de Santa Maria y su familia de conversos. Historia de la judería de Burgos y de sus conversos más egregios. Madrid, 1952.

Las ediciones más satisfactorias del Defensorium Unitatis Christianae son la de M. Alonso, Libellus seu defensorium unitatis christianae. Madrid, 1943, y la más reciente de Guillermo VERDíNDíaz, Alonso de Cartagena y el Defensorium Unitatis Christianae (Introducción histórica, traducción y notas). Universidad de Oviedo, 1992.

6. Guillermo Verdin-Díaz, Alonso de Cartagena y el Defensorium Unitatis Christianae, pág. 82
} 
canzaría su propósito de entrevistarse con el papa, ya que se lo impidió la actuación del cardenal español fray Juan de Torquemada, quien también intervendría inmediatamente en el debate doctrinal.

Así las cosas, en septiembre de 1449 el papa Nicolás V otorgó la bula Humani generis inimicus, en la que se condenaba sin paliativos la división entre cristianos viejos y nuevos, así como cualquier limitación impuesta a los judeoconversos para el acceso a cargos públicos y dignidades eclesiásticas. La pena de excomunión iría aparejada a la calificación de heterodoxia para toda doctrina que defendiera cualquier tipo de distinción o de separación entre cristianos.

La condena pontificia presenta también un marcado contenido temporal, por cuanto la excomunión dictada contra Pero Sarmiento y sus seguidores era proclamada también como castigo por su levantamiento frente a la autoridad legítima del rey ${ }^{7}$.

\section{LA INTERVENCIÓN DE LOPE DE BARRIENTOS EN EL DEBATE DOCTRINAL}

El obispo de Cuenca debía seguir con vivo interés el curso del debate doctrinal relativo a los judeoconversos, pero da la impresión de que su interverción en el mismo no se produjo sino inducida por algunos personajes que tomaban parte activa en el mismo.

Este es el caso del deán D. Francisco de Toledo, cristiano nuevo, quien con el tiempo llegaría a ser obispo de Coria. El deán toledano había participado activamente en diversas controversias filosóficas y teológicas en torno a la cuestión de los cristianos nuevos, y tras la promulgación de la SentenciaEstatuto se vio obligado a abandonar la ciudad de Toledo refugiándose en la población toledana de Santa Olalla, donde escribió una refutación de dicho edicto, que no ha llegado hasta nosotros. Poco después redactó un largo escrito, titulado Apologético, que dirigió al obispo de Cuenca, fray Lope de Barrientos, y que tampoco se conoce. No cabe la menor duda de que el deán toledano buscaba con este escrito forzar la intervención directa en la polémica del obispo conquense, quien gozaba de una privilegiada posición en la corte del rey Juan II, así como de una importante capacidad de influencia sobre el príncipe don Enrique, de quien había sido preceptor.

\footnotetext{
Sobre las bulas del papa Nicolás $V$ en relación a los judeoconversos castellanos, es interesante el trabajo de $V$. BELTRÁN DE HEREDIA, «Las bulas de Nicolás $V$ acerca de los conversos de Castilla", en Sefarad, XXI (1961), págs. 22-47.
} 
En una línea muy parecida se sitúa una obra mejor conocida, la Instrucción que en octubre de 1449 dirigió el Relator del Consejo Real Fernán Díaz de Toledo a Lope de Barrientos ${ }^{8}$.

En esta obra el Relator, de ascendencia judía, se queja amargamente de las persecuciones a que eran sometidos los conversos toledanos, y solicita directamente la intervención del obispo de Cuenca, debido a su gran capacidad de influencia en la corte. Su cargo de Relator le permite aportar documentos de gran interés, que hacen de esta obra una de las más sólidas, desde el punto de vista argumental, de cuantas fueron redactadas a lo largo de este debate.

Combate duramente la Sentencia-Estatuto de Pero Sarmiento, y señala que el impedimento a los cristianos nuevos de ejercer oficios públicos sólo es justificable en los casos de aquéllos que se demuestre que han judaizado. Así mismo se lamenta de la política discriminatoria impulsada por las autoridades toledanas contra los judeoconversos, porque estaba provocando un parón en el proceso de conversiones al cristianismo, ya que los conversos comenzaban a afirmar públicamente que se habían equivocado al aceptar la religión cristiana, pues ellos eran peor tratados que los propios judíos.

Junto con su Instrucción, el Relator envió al obispo de Cuenca la traducción romanceada de la bula Humani generis inimicus, así como una copia de una carta-privilegio del rey Enrique III en favor del mantenimiento de los judeoconversos en los oficios públicos, con el fin de que se las mostrara al príncipe don Enrique. También adjuntaba a su Instrucción dos breves que el papa había dirigido recientemente al rey Juan II y al príncipe don Enrique, que confirmaban en favor de los judeoconversos la doctrina que, en relación con su participación en el ejercicio de oficios públicos, se expresaba claramente en la carta-privilegio de Enrique III a la que acabo de referirme, así como en las Partidas y en el Ordenamiento de Alcalá, en los decretos del Concilio de Basilea y, en general, en toda la doctrina tradicional de la Iglesia.

Sumamente interesante, además de acertada, es la afirmación del Relator de que no cabe denominar «conversos» a los hijos y nietos de personas convertidas al cristianismo, por cuanto desconocían ya totalmente

8 La figura del Relator Fernán Díaz de Toledo es analizada por Nicholas G. Round, «Politics, style and group attitudes in the "Instrucción del Relator"», en Bulletin of Hispanic Studies, XLVI (1969), págs. 289-319.

La edición decimonónica de D. Fermín Caballero de la Instrucción del Relator puede consultarse en la edición del Defensorium Unitatis Christianae de M. Alonso. 
la religión judía. En su opinión, el término de «conversos» es únicamente aplicable a las personas convertidas directamente al cristianismo, pero en ningún caso a sus descendientes. Con el tiempo, sin embargo, terminaría imponiéndose el criterio opuesto, pues los «estatutos de limpieza de sangre» remontarán hasta la cuarta generación la «mancha» de judaísmo.

Finalmente, incluye una larga relación de personas de linaje de cristianos nuevos que forman parte de algunas de las más esclarecidas familias del reino, por lo que - afirma el Relator - la injuria que los cabecillas de la revuelta toledana hacían a los judeoconversos de esa ciudad afectaba al reino de Castilla en general.

El Relator concluye su Instrucción solicitando la mediación del obispo de Cuenca ante el príncipe don Enrique, e instándole a que, si lo consideraba oportuno, procurara la restitución de todos los bienes que habian sido arrebatados en la revuelta de 1449 a los judeoconversos toledanos.

Cabe preguntarse a qué obedecía el requerimiento que en este momento hacía a Lope de Barrientos el Relator Fernán Díaz de Toledo, que venía a unirse al que algún tiempo antes le había hecho en el mismo sentido el deán toledano Francisco de Toledo.

La respuesta se encuentra, muy probablemente, en un escrito que Barrientos había dirigido a un bachiller llamado Alfonso Martínez, a quien él mismo identifica como un clérigo toledano y familiar suyo, y que previamente había formulado una consulta al obispo de Cuenca en relación con la "Cuestión conversa» 9 . A este escrito se refiere también Barrientos en su obra titulada Contra algunos zizañadores de la nación de los convertidos del pueblo de Israel, a la que me referiré seguidamente.

En esta Respuesta Barrientos se muestra favorable a que los conversos desempeñen cualquier tipo de oficio público, pero introduce una restricción en cuanto al ejercicio de dignidades eclesiásticas y del obispado, lo que no deja de llamar la atención en una figura tan abierta a la libre actuación de los judeoconversos. Parece muy probable que Barrientos se refiriera exclusivamente a convertidos directamente del judaísmo y no a descendientes de los mismos, en la misma línea que el Relator.

La argumentación que se hace en este escrito es de carácter escriturístico y patrístico, realizando una interpretación favorable a la libre actua-

9 Como me informó el profesor José Manuel Nieto Soria, este escrito del obispo Lope de Barrientos al bachiller Alfonso Martínez se conserva en la Sección de Manuscritos de la Biblioteca Nacional de Madrid, con la signatura 1181 , fols. $128 v^{2}-145 r^{2}$. 
ción de los conversos de diversos textos jurídicos y conciliares, en particular del tan debatido pasaje del IV Concilio de Toledo y de las decretales.

Además de su propia actitud personal, en la toma de postura de Barrientos en favor de los conversos pudieron influir, en mi opinión, varias circunstancias:

1. En primer lugar, y como figura destacada de la Iglesia que era, Barrientos se alineaba decididamente con la postura oficial de la Iglesia al respecto, expresada de forma inequívoca en la bula de Nicolás $\vee$ Humani generis inimicus.

2. Desde un punto de vista político, no cabe ninguna duda de la oposición manifiesta de Barrientos a cualquier acción que pudiera ir en contra del principio de la autoridad regia, a cuyo fortalecimiento él había contribuido decididamente.

3. Por otra parte, los excesos de la revuelta toledana no podían dejar indiferente a un espíritu como el del obispo de Cuenca, lo que se expresa claramente en el capítulo primero del año cuadragésimo cuarto de la Crónica de Juan II, del doctor Galíndez de Carvajal ${ }^{10}$.

4. Por último, y pese a que nada seguro puede afirmarse al respecto, es posible que fray Lope de Barrientos tuviera un antecedente familiar judío, más o menos lejano.

10 En dicha Crónica se relata una conversación que mantuvo Lope de Barrientos con Pero Sarmiento, en la que le transmitió el deseo del príncipe de que le hiciera entrega de la ciudad y que seguidamente la abandonara. Como quiera que Sarmiento se exasperara ante esta propuesta, el obispo «como era hombre robusto y de mal sufrimiento, díxole:

Vos, Pero Sarmiento, hecistes gran aleve e desobediencia al Rey vuestro Señor, habiendo fiado de vos esta su cibdad de Toledo, y gela habeis tenido tomada, e habeis robado y destruido e muerto muchos hombres cibdadanos honrados de esta cibdad, e sobretodo habeis quebrantado las Iglesias y los Monesterios, sacando los bienes de los cibdadanos que alli tenian metidos por los amparar y defender de vos. E vos no parando mientes a Dios, ni a la justicia, ni a vuestra conciencia, todo lo robábades y metiades en el alcazar; e no vos bastó tomar los bienes, mas aun haciades justicia de hombres cibdadanos honrados, a los unos ahorcando, a los otros quemando sin ser oidos, ni haber causa ninguna para los justiciar; a otros levantábades cosas que nunca pensaron, e como teníades por vos la justicia y los escribanos, buscábades testigos malfechores contra ellos, e como todos vos temian, diciendo que vos les mandábades, con esta color tomábades les sus bienes.Todas estas cosas son notorias a Dios, e las sabe bien el Rey y el Príncipe, e todos los de su Consejo; e aun mas vos digo, que con vuestra iniqua lengua habeis mucho deshonrado la Magestad Real, saliendo con mano armada contra vuestro Rey y Señor, quitándole el título de Rey; e allende desto herrojábades y teniades presos en bovedas en el alcázar muchos hombres honrados, y dueñas viudas, y casadas, donde no podían ver el cielo, porque mas prestamente los rescatásedes».

BIBLIOTECA DE AUTORES ESPAÑOLES, Tomo LXVIII. Crónicas de los Reyes de Castilla, vol. II (Madrid. Ediciones Atlas, 1953), pág. 670. 
Como apoyo de esta hipótesis cabe señalar que el propio Barrientos incorpora su apellido a la relación de linajes con sangre judía que había incluido el Relator en su Instrucción y que éste, sin duda por prudencia, no había hecho figurar.

Al requerimiento del Relator contestó Lope de Barrientos con un breve tratado, titulado Contra algunos zizañadores de la nación de los convertidos del pueblo de Israel, que escribió en romance, probablemente con el fin de conseguir una mayor difusión de los principios que en él exponía ${ }^{11}$.

Este tratado está redactado en forma de memorial o de carta dirigida a un sobrino suyo, y su característica más sobresaliente es su escasa originalidad de forma que, como señala el profesor Benito Ruano, se limita prácticamente a repetir, de forma casi literal, los argumentos expresados por el Relator ${ }^{12}$.

Pese a que Juan de Mata Carriazo propone para este tratado la fecha de $1451^{13}$, parece mucho más verosímil la tesis que sostiene el profesor Benito Ruano, quien lo data en octubre de 1449 , por cuanto es necesariamente anterior a la refutación que del mismo hizo el bachiller Marcos García de Mora en su Memorial de agravios, fechado en noviembre de 1449. Así mismo, Barrientos prevé en su escrito la reacción que va a provocar en los sublevados toledanos la bula de Nicolás $\mathrm{V}$, promulgada en septiembre de 1449, por lo que también tiene que ser posterior a la misma.

En definitiva, considero acertada la propuesta del profesor Benito Ruano, de forma que el tratado sería redactado, probablemente, a lo largo del mes de octubre de 1449, un mes antes de la muerte del bachiller Marcos García de Mora y de la expulsión de Pero Sarmiento de la ciudad de Toledo, hecho este último en el que la influencia del obispo de Cuenca debió ser decisiva, según se narra en el capítulo primero del año cuadragésimo cuarto de la Crónica de Juan II, del doctor Galíndez de Carvajal ${ }^{14}$.

\footnotetext{
11 Este tratado del obispo Lope de Barrientos ha sido publicado por L. A. GETino, Anales Salmantinos. I. Vida y obras de Fray Lope de Barrientos. Salamanca, 1927, págs. 181-204.

12 Eloy Benito Ruano, Los origenes del problema converso, pág. 60.

13 Juan de Mata Caraiazo, Refundición de la crónica del Halconero. Madrid, 1946 (en con-

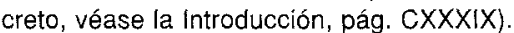

14 Así refiere la Crónica de Juan II estos acontecimientos:

"Y desque el obispo vido que ninguna cosa le respondió, díxole: Pero Sarmiento, a mí parece e vos doy por consejo que prestamente vos vayais desta cibdad, que esto es lo que cumple a vos; que si no fuese por el seguro que el Príncipe vos ha dado, segun las cosas abominables, feas y malas habeis hecho en esta cibdad, vuestra persona estaria en gran peligro. A esto respondió Pero Sarmiento: Señor obispo, yo no puedo atapar las bocas de las gentes: estaré esta noche con
} 


\section{LA ÚLTIMA FASE DEL DEBATE DOCTRINAL: EL MEMORIAL DE AGRAVIOS DEL BACHILLER MARCOS GARCÍA DE MORA, $Y$ EL TRACTATUS CONTRA MADIANITAS ET ISMAELITAS DEL CARDENAL TORQUEMADA}

No es difícil hacerse idea del terrible efecto que la corriente de reprobación doctrinal -especialmente la bula pontificia- hubo de tener en el ánimo de los sublevados toledanos, en un momento en el que comenzaba a cundir la desmoralización interna, como resultado de los excesos de la revuelta. Estas circunstancias obligaban a una reflexión, más o menos serena, una vez pasada la efervescencia de los primeros momentos.

En definitiva, los sublevados comprendían la necesidad de disponer de un aparato legal que legitimara su actitud y que debía ser, a un tiempo, de carácter político, teológico y jurídico. Esta necesidad es la que trató de cubrir el bachiller Marcos García de Mora, apodado despectivamente por sus adversarios «Marquillos de Mazarambroz», con su famoso Memorial de agravios.

El profesor Benito Ruano sitúa la fecha de redacción de esta obra en los últimos días de octubre o en los primeros de noviembre de 1449, pues es posterior no sólo a la bula pontificia del 24 de septiembre de 1449, sino también a la Instrucción del Relator y al tratado de Lope de Barrientos Contra algunos zizañadores de la nación de los convertidos del pueblo de Israel, obras éstas que parecen haber sido redactadas en el mes de octubre de ese mismo año ${ }^{15}$.

El Memorial del bachiller García de Mora surgió como una reacción furibunda frente a las condenas pontificia y regia, centrando sus ataques en las figuras del condestable don Álvaro de Luna y del Relator; a este último lo califica de persona ruin, herética y despreciable, lo que es una señal inequívoca del daño que había hecho a los sublevados la crítica de los proconversos. La refutación del tratado de Barrientos quedaba en un segundo lugar, sin duda porque García de Mora era consciente de que esta obra se había basado, sustancialmente, en la Instrucción del Relator; así, más que una refutación del tratado de Barrientos, propiamente dicha, el bachiller se limitó a lanzar alguna invectiva contra la figura del obispo de Cuenca, por su toma de postura en relación con la revuelta toledana.

\footnotetext{
el Señor Príncipe, e pues su seguro tengo, demandaré a Su Alteza licencia, e partiré esta noche desta cibdad, y llevaré todo lo que aquí tengo".

BIBLIOTECA DE AUTORES ESPAÑOLES, Tomo LXVIII, Crónicas de los Reyes de Castilla, vol. Il (Madrid, Ediciones Atlas, 1953), pág. 671.

15 Eloy Benito RuANo, Los orígenes del problema converso, págs. 62-63.
} 
Se trata de un documento muy extenso, que abunda en citas bíblicas, canónicas y jurídicas, y que trasluce claramente la profunda animosidad y el odio de los cristianos viejos toledanos hacia sus convecinos judeoconversos. El bachiller se esfuerza en refutar la bula de excomunión pontificia y las disposiciones regias contra los rebeldes, defiende la actuación de Pero Sarmiento y justifica la revuelta, cuya única finalidad habría sido levantarse contra los abusos que se cometían contra el pueblo, expulsar a los tiranos y extirpar las herejías. Por lo tanto, no debía ser vista como una rebelión contra la autoridad regia, sino como una acción encaminada a la defensa de los intereses populares, por lo que solicitaba del papa y del rey la revocación de sus escritos de condena.

En su escrito, el bachiller García de Mora dirige palabras de recriminación al príncipe don Enrique, a quien trata de hacer comprender que ha sido engañado por el obispo Lope de Barrientos, quien le ha inducido a faltar a los juramentos y promesas que anteriormente había hecho por escrito a la ciudad de Toledo. Se trata éste de un dato más que permite comprobar el importante papel político que jugó el obispo de Cuenca en la resolución de la revuelta toledana, así como la capacidad de influencia sobre el príncipe que le conferían sus oponentes dialécticos y que, indudablemente, es un reflejo de la que en realidad poseía.

El profesor Benito Ruano califica de poco consistente teológica, jurídica y apologéticamente la argumentación del bachiller Marcos García de Mora, considerando el valor de su obra muy inferior al de otros tratados de la época que se sitúan en una misma línea de combate a los conversos ${ }^{16}$. Su principal interés radica, precisamente, en que ilustra con suma claridad el carácter de la revuelta toledana, así como el clima crispado contra los conversos. En cualquier caso, la repercusión del Memorial de agravios fue mucho mayor de lo que cabría suponer en función de su escasa calidad, de forma que se transformó en uno de los hitos de una corriente de opinión que alcanzaría gran éxito en Castilla.

Tras el Memorial de agravios del bachiller Marcos García de Mora hizo su aparición el tratado del cardenal Juan de Torquemada titulado Tractatus contra Madianitas et ismaelitas adversarios et detractores filiorum qui de populo israelitico originem traxerunt, fechado en Roma en $1450^{17}$.

16 Eloy Benito Ruano, Los origenes del problema converso, pág. 65.

17 Para acercarse al conocimiento de la figura del cardenal Juan de Torquemada es útil el trabajo de Nicolás LóPEz MARTínez, "El cardenal Torquemada y la unidad de la lglesia", en Burgense, 1 (1960), págs. 45-71.

La mejor edición del Tractatus contra Madianitas et Ismaelitas corresponde a N. LóPEZ Martinez y V. Proaño GIL, quienes la publicaron en Burgos, en el año 1957. 
El cardenal Torquemada, dominico, hombre de confianza del papa Nicolás $\mathrm{V}$, hace en esta obra una refutación, casi punto por punto y argumento por argumento, del Memorial de García de Mora, interpretando en sentido opuesto las citas de las Sagradas Escrituras, glosas y comentarios del derecho justinianeo, cánones, decretales y leyes del reino que presentaba el bachiller en su Memorial.

En los últimos capítulos del Tratado señala la improcedencia de la distinción entre cristianos viejos y cristianos nuevos, especialmente por lo que respecta al desempeño de cargos públicos, por cuanto todos son miembros de una misma Iglesia. En una toma de actitud muy similar a la del Relator, a la que antes hacía referencia, interpreta los cánones del IV Concilio de Toledo y el pasaje del Fuero Juzgo que esgrime García de Mora como argumentos justificativos de la limitación de derechos a los judeoconversos como aplicables sólo a los conversos que apostataran, pero en ningún caso a los que se mantenían firmes en la nueva fe, y mucho menos a los nacidos en ella, a los que ya no se podía denominar propiamente conversos.

Este Tratado está considerado como una de las contribuciones más interesantes al debate doctrinal, en el que se hace patente el elogio encendido hacia los hebreos, lo que, en opinión de algún autor, podría explicarse por los orígenes judaicos del cardenal.

\section{PRINCIPALES CONCLUSIONES EN TORNO AL DEBATE DOCTRINAL SOBRE LOS JUDEOCONVERSOS}

De cuanto hasta aquí se ha dicho es fácil deducir que la integración de los judeoconversos en la sociedad hispana fue un asunto profundamente controvertido, y que constituyó una de las cuestiones más relevantes, social y religiosamente, en la Castilla del siglo XV.

Pese a todo, las propuestas que los defensores del principio de la unidad dentro del cristianismo formularon a lo largo de este debate doctrinal pueden considerarse las únicas realmente constructivas para una auténtica solución del problema converso. Y de ahí la importancia que cobran los tratados de Fernán Díaz de Toledo, Lope de Barrientos, Alonso de Cartagena y el cardenal Torquemada, mucho más allá del debate concreto para el que fueron redactados, pues el gran tema de fondo era el de la integración social y religiosa de los judeoconversos.

La Sentencia-Estatuto de Pero Sarmiento y el Memorial de agravios del bachiller Marcos García de Mora denuncian los problemas políticos, 
económico-sociales y religiosos que, en su opinión, sufría el reino de Castilla, y en particular la ciudad de Toledo, y que ellos achacaban al mal gobierno de don Álvaro de Luna y de sus colaboradores judeoconversos, por lo que solicitaban al rey la destitución de todos ellos.

Asimismo, Sarmiento y el concejo toledano acusaban a los conversos de judaizar en secreto, de ambición económica y de arrogancia, acusaciones éstas que habían calado muy hondo en el sentimiento popular, como puede constatarse a través de algunas obras del momento, como las crónicas de Alonso de Palencia o de Andrés Bernáldez.

Por el contrario, la Instrucción del Relator Fernán Díaz de Toledo, y los tratados de Lope de Barrientos, Alonso de Cartagena y del cardenal Torquemada se centraban, fundamentalmente, en el problema religioso, pasando por alto otro tipo de cuestiones de carácter político o económico. Aunque existen otras obras que se sitúan en una misma línea de defensa de la causa de los judeoconversos ${ }^{18}$, éstas son, indudablemente, las más representativas; estrechamente relacionadas entre sí, se basan en muy similares tramas argumentales.

Desde un punto de vista meramente religioso, la Sentencia-Estatuto y el Memorial de agravios acusaban a los judeoconversos de judaizar, 10 que justificaría su exclusión de los cargos públicos y su incapacitación para actuar como testigos en juicios seguidos contra cristianos viejos, en virtud de una aplicación estricta de los decretos del IV Concilio de Toledo.

Por el contrario, Fernán Díaz de Toledo, Barrientos y Cartagena defendían la ortodoxia del comportamiento religioso de la inmensa mayoría de los judeoconversos, y calificaban de difamaciones heréticas las acusaciones genéricas que realizaban Sarmiento y Marquillos de Mazarambroz.

Cartagena denunciaba a las personas y autoridades que, de ser ciertas las acusaciones formuladas por Sarmiento y García de Mora, no hacían nada por impedirlo, y no ocultaba que le preocupaban más las dificultades que para la unidad de los cristianos pudiera generar el rechazo generalizado hacia los conversos, que la posible heterodoxia en el comportamiento religioso de algunos individuos aislados.

El debate se centraba, en buena medida, en torno a la cuestión concreta de si el pasaje del IV Concilio de Toledo que justifica la postergación

18 A este respecto es interesante la obra compuesta entre 1455 y 1465 por un bachiller Palma, que hace unos años dio a conocer R. GONZÁLVEZ Ruiz en un trabajo titulado «El bachiller Palma, autor de una obra desconocida en favor de los conversos", que aparece publicado en las actas del / Simposio Toledo Judaico, Madrid, 1973, vol. II, págs. 31-48. 
de las personas de etnia judía, afectaba a los judeoconversos -es decir a las personas de linaje judío en general-, como defendían Sarmiento y Marquillos, o tan sólo a los judíos y a los conversos que judaizaran, como afirmaban Cartagena, Barrientos y el cardenal Torquemada.

La posición oficial de la Iglesia al respecto, reflejada en la obra de estos autores, no dejaba lugar a ninguna duda. En su bula Humani generis inimicus, el papa Nicolás $V$ había dejado sentado el principio que afirmaba que todas las personas que se convirtieran sinceramente al cristianismo habrían de ser admitidas en todos los oficios, cargos y dignidades, con los mismos derechos que los cristianos viejos. Únicamente podrían ser excluidos quienes no guardaran debidamente los principios de la religión cristiana; pero incluso en estos casos era la autoridad competente quien debía juzgar, y nadie estaba legitimado a actuar por su cuenta como, en definitiva, había hecho Sarmiento en la ciudad de Toledo. En este punto hay que señalar que, como ya indiqué en otro lugar, en el escrito que el obispo Lope de Barrientos dirigió al bachiller Alfonso Martínez se excluía a los conversos del ejercicio de dignidades eclesiásticas y del obispado, aun cuando es posible que no se refiriera a los descendientes de conversos, sino a los directamente convertidos desde el judaísmo.

En resumen, mientras Sarmiento y García de Mora se esforzaban en demostrar el carácter pérfido de los conversos, a los que denigraban continuamente, Fernán Díaz de Toledo, Barrientos, Cartagena y el cardenal Torquemada solicitaban su protección, de acuerdo con el derecho y la legislación civil, así como con el derecho canónico y la doctrina universal de la Iglesia.

Así las cosas, una adecuada solución del conflicto toledano pasaba por la aplicación estricta de la ley, mediante el estudio de las causas por la justicia y el castigo y apartamiento de sus cargos de los que resultaran culpables de los desmanes de la revuelta.

Pero la justicia no llegaría finalmente, porque la solución del enfrentamiento entre cristianos viejos y judeoconversos exigía la aplicación de medidas rigurosas, que no podía llevar a cabo una monarquía débil en extremo.

Las propuestas conciliadoras formuladas por Fernán Díaz de Toledo, Barrientos, Cartagena y el cardenal Torquemada no serían finalmente tenidas en cuenta, quizá porque llegaban demasiado tarde, en un momento en el que la fusión sin fisuras entre cristianos viejos y nuevos ya no era posible. En adelante los judeoconversos serán cada vez más rechazados socialmente, de forma que estamos en los prolegómenos de la exigencia de la «limpieza de sangre» para el acceso a ciertos cargos, oficios y dignidades. En definitiva, y pese a la indubitable doctrina de la Iglesia al res- 
pecto, se imponía a marchas forzadas la división en el seno de la sociedad hispanocristiana.

La solución que en este momento se daría al problema converso obedecía más al pragmatismo político del monarca, que a principios de justicia y legalidad.

El 28 de octubre de 1450, el rey Juan II solicitó, y obtuvo, de Roma la suspensión de la bula Humani generis inimicus, mediante el otorgamiento de una nueva bula el 20 de noviembre de 1450 -Regis pacifici-, por la que quedaban anulados los interdictos y censuras lanzados contra las autoridades toledanas, precisamente a instancia del monarca castellano. Incluso se levantaba también la excomunión que había sido lanzada contra Pero Sarmiento.

Un año después, el 20 de noviembre de 1451, el papa Nicolás $V$ promulgó una nueva bula - Inter curas-, en la que se ordenaba proceder por vía de inquisición contra todos los conversos sospechosos de judaizar. Pese a que esta bula no llegaría nunca a hacerse realmente efectiva, es ya claramente indicativa del clima dominante, que conduciría al cabo de unos decenios a la creación del Tribunal de la Inquisición.

La actuación de Juan II es demostrativa de una escasa inteligencia política, pues retrocedió excesivamente pronto de su inicial toma de postura ante la revuelta toledana; antes incluso de que la ciudad se le entregara ya había otorgado su perdón a los rebeldes, y nada más entrar en la ciudad ratificó la medida que excluía a los judeoconversos del ejercicio de cargos públicos.

No cabe la menor duda de que esta forma de actuar de Juan II es un reflejo de su debilidad y obedecía a un intento por frenar los gérmenes de la rebeldía popular, cediendo para ello, de forma demagógica, a las presiones antijudías. Es ésta una táctica que también seguiría más tarde el rey Enrique IV, condicionado por la extrema debilidad de la autoridad monárquica.

Junto a los textos en pro y en contra de la exclusión de los conversos, algunas obras literarias del momento arrojan también mucha luz sobre el trasfondo socio-religioso del antijudaísmo castellano. Son, entre otras, las anónimas Coplas del Provincial o el Cancionero de Baena, de Rodrigo de Cota. Especial interés tienen algunas sátiras cuyos principales personajes son conversos que viven ocultamente como judíos, y cuyo bautismo ha sido meramente ficticio, con el fin de medrar ${ }^{19}$.

19 Una de estas sátiras fue dada a conocer por H. PFLAUM, «Une anciènne satire espagnole contre les Marranes", en Revue d'Études Juives, LXXXVI, 1928, pp. 131-150, y consiste en una parodia de la concesıón de un privilegio real a un hidalgo, cristiano viejo, que le autorizaba a vivir 
La polémica en torno a la integración de los conversos es expresiva de la gran confusión existente en la sociedad hispana durante la segunda y la tercera generaciones siguientes a las conversiones masivas de fines del siglo XIV y principios del siglo XV, en un momento en el que la asimilación de los convertidos a la sociedad cristiana debería ser ya una realidad.

En este sentido, los levantamientos anticonversos de 1449 en Toledo y Ciudad Real constituyen la primera manifestación de una oposición violenta por parte de los cristianos viejos al proceso de integración de los judeoconversos en la sociedad cristiana, que se reproduciría en los años sesenta y setenta del siglo $x v$ en diversos movimientos urbanos anticonversos ${ }^{20}$, que en algunos casos fueron acompañados del establecimiento de ordenanzas y estatutos limitadores de la libertad y de la capacidad de actuación de los cristianos nuevos.

En conclusión, el debate público en torno a los judeoconversos conoce su punto álgido en el reinado de Juan II. En tanto que los círculos de conversos y sus partidarios defendían un trato tolerante hacia los recién convertidos, su educación en los principios de la religión cristiana y su plena integración en la sociedad hispanocristiana, otros grupos - generalmente de cristianos viejos, aunque tampoco son raros los descendientes de conversos- exigían medidas rigurosas contra los judaizantes, sin tener en cuenta los aspectos sociales del problema.

Este segundo sector sería el que terminaría por imponerse, consiguiendo la instauración de la Inquisición y el apartamiento de los conversos declarados culpables de los puestos que ocupaban en la sociedad. Esta actitud, llevada a la práctica en el último cuarto del siglo $\mathrm{xv}$, tuvo sus primeras formulaciones teóricas unos decenios antes, en torno al debate doctrinal sobre los acontecimientos toledanos. Es en este momento cuando se sientan las primeras bases para la definitiva «solución» de los problemas judío y converso, que por muchas razones serán fundamentales en la sociedad hispana del siglo xv y de los primeros tiempos de la Modernidad.

\footnotetext{
y comportarse como los conversos. De este modo, el autor refiere detalladamente las principales acusaciones populares y los arquetipos de los judeoconversos.

20 En 1465 en Sevilla; en 1467 en Burgos y Toledo; en 1468 en Sepúlveda; en 1469 son asaltados los recaudadores conversos en Tolosa; en 1473 en Jaén, Córdoba, Montoro, Écija, Andújar, Úbeda, Bujalance, La Rambla y otras poblaciones del reino de Córdoba; en 1474 en Segovia y Ciudad Real.
} 